\title{
Propósitos y funciones de la televisión en la era digital a partir de un análisis de la televisión peruana
}

Purposes and functions of television in the digital age based on an analysis of peruvian television

\author{
Mercedes Milagro Sarapura Sarapura mercedicosas@hotmail.com \\ http://orcid.org/0000-0003-1005-2376 \\ Universidad de San Martín de Porres (Perú)
}

\section{Resumen}

La discusión sobre los propósitos y funciones de la televisión sigue su curso en el mundo de la convergencia, porque además de que es aún el medio de comunicación con mayor sintonía después de la radio-, al llegar a ser digital, ha supuesto cambios de hábitos de uso que demandan mayor claridad en cuanto a su papel en la vida cotidiana de millones de consumidores.

Esta aproximación, de alcance descriptivo y de enfoque cualitativo según el método deductivo analítico, intentar hacer un aporte sobre la situación de la televisión en cuanto a sus funciones: 
entretener e informar, así como en cuanto a su propósito educativo que desde siempre ha supuesto inagotables polémicas, a partir del caso de la televisión peruana.

Así pues, tras una revisión de los contenidos que propone la televisión de señal abierta, se evidencia la crisis que atraviesa la televisión en general por insuficiente calidad ya entre los géneros de entretenimiento y de información, que conllevan, como consecuencia, una desatención a propósitos tan trascendentales como el de orientar o, más aún, el de educar. Con todo ello, la televisión digital se presenta como la nueva alternativa que pondera al medio más que como informativo, de entretenimiento.

Palabras clave: Televisión; ética; información; entretenimiento; educación; receptores; convergencia mediática.

\begin{abstract}
The discussion about the purposes and functions of television continues its course in the world of convergence, because in addition to being still the most tuned means of communication -after the radio-, when it becomes digital, it has involved changes in habits of use that demand greater clarity regarding its role inserted in the daily life of millions of consumers.

This approach, of descriptive scope and qualitative approach according to the analytical deductive method, tries to make a contribution on the television situation in terms of its functions: entertain and inform, as well as in terms of its educational purpose that has always been inexhaustible controversies, from the case of peruvian television.

Thus, after a review of the contents proposed by open-signal television, the crisis that television is experiencing in general due to insufficient quality and between the genres of entertainment and information is evident, which entails, as a consequence, an inattention to purposes as transcendental as that of orienting or, even more, that of educating. With all this, digital television is presented as the new alternative that ponders the media rather than as an informative, entertainment.
\end{abstract}

Keywords: Televisión; ethics; information; entertaiment; education; receptors; media convergence. 
Desde siempre se ha visto una distancia entre lo que se hace y lo que se debe hacer en la televisión y esta situación no ha cambiado en la era digital sino posiblemente se ha intensificado; no obstante, lo cierto es que los propósitos y funciones de la televisión basados en los valores humanos y la ética que resultan inamovibles porque siempre son los mismos, han supuesto una discusión en torno a cuán viables han sido unos y otros.

En la actualidad se presenta una televisión que, a pesar de la convergencia mediática, es aún el medio de comunicación que llega a más gente y que salva la brecha digital, es decir, entre los que saben y utilizan las tecnologías y quienes no, con lo que se confirma, pese a los cambios, la importancia que aún tiene en la sociedad; y por otro lado, se tiene una televisión de creciente robustecimiento en Internet, que conlleva sus mismas funciones y propósitos y con ellos, nuevos aciertos y desafíos.

La televisión es un medio de generaciones, hasta los años ochenta, sin duda era el eje del entretenimiento, pero es a partir de esa misma década en que resulta eclipsada, como todos los demás medios tradicionales, por la llegada de internet. La circunstancia actual de la televisión mundial, conocida como la televisión de señal abierta o cerrada, de uso tradicional, cuyo soporte final es el electrodoméstico televisor, está en crisis. Los jóvenes no usan la televisión del modo tradicional, pero consumen televisión a través de internet y es en este punto culminante de la realidad actual en que se amerita una observación de cómo la televisión cumple con sus funciones y propósitos en el curso de la nueva dimensión por la que se encamina.

Desde los inicios en la investigación de la comunicación Lazarfeld (Mattelart, 2005) propuso su teoría de los dos pasos, con la que sostenía que los medios de comunicación influyen poderosamente en los receptores, aunque no de manera directa. El proceso de acuerdo a su paradigma, comenzaba con el mensaje mediático que apela a la atención de los líderes de opinión, sujetos confiables y poseedores de influencia en sus entornos, quienes a su vez transmitirían el mensaje a dichos entornos o grupos sociales. Estos líderes estarían entre las audiencias, es decir, aquellas personas en los grupos que destacan por sus conocimientos; y en los mismos medios de comunicación tales como los artistas, periodistas o intelectuales. Este esquema resulta evocado cuando desde otras perspectivas teóricas se ha llegado a la misma conclusión, la fuerza persuasiva de la televisión (y de los otros medios) llega a la gente a través de los líderes con quienes el entorno interactúa y toma resoluciones.

En esa misma dirección, Ranciére (Yazigi, 2011: 278) desmitifica las jerarquías del conocimiento cuando plantea la emancipación del espectador como sujeto pensante, capaz de discernir, aportar y llegar a sus propias conclusiones; y desde la filosofía Gomá (YouTube, 2015) defiende la poderosa influencia del ejemplo personal. Es en esta precisa instancia en la 
que se halla una televisión, como parte de la corriente convergente de Internet, que propone más que una influencia directa imponente como la de sus inicios, una influencia más bien sutil, cercana, permanente y, por todo ello, de una eficacia sin precedentes.

Los líderes de opinión propuestos en las últimas décadas por la televisión tradicional, resultan líderes decadentes, aunque muy bien preservados porque para muchos sectores de la sociedad, la televisión es todavía la única fuente de información; no obstante, la televisión digital es el lugar de una generación de líderes de opinión que se acercan a sus audiencias a través de diversos canales de internet como los blogs, las páginas web y las redes sociales en general.

El cine nació como el imponente medio de comunicación de masas cuya misión y fortaleza era el entretenimiento, la televisión asumió la misión del entretenimiento y el de la información, es por ello que el género documental nacido en el cine cobró gran relevancia en la televisión porque se asumía que este género era primordialmente informativo y consecuentemente entretenido.

Al cabo, internet converge todos los medios de comunicación y asume también sus funciones, no obstante, aquí la preponderancia de la función de entretenimiento adquiere nuevos relieves al igual que el informativo. Mientras que la televisión convencional o analógica está en su declive, en el que sus desgastados géneros de entretenimiento reclaman la pifia cada vez más intensa de sus otrora aficionados públicos y en el que sus géneros informativos resultan insuficientes, la televisión digital aliada con los atributos de Internet despega a propuestas informativas y de entretenimiento que se presume serían mucho más viables con el propósito educativo.

La televisión tradicional afronta una permanente tensión entre su función social y su función comercial, aspectos que deben ser muy bien diferenciados y asumidos si lo que se quiere es partir hacia una televisión digital de calidad. Al respecto Cabrera (2006: 8) sostiene que "el significado de la televisión como ejercicio comercial, como empresa lucrativa y negocio, se impone entre los creadores de contenidos como una de las representaciones más compartidas y generalizadas". El autor observa que las consideraciones de tipo ético, cultural o de servicio público serían secundarias ya que la experiencia es lo que reafirmaría en los realizadores una concepción de la televisión como un negocio.

No obstante, es de considerar que la función social supone propósitos educativos, culturales y de entretenimiento que a su vez se constituirían como bienes cualitativos y parte intrínseca de los contenidos mediáticos, sin los cuales estos carecerían de sentido y sustancia aun cuando la función comercial sería la que se busca; ese sentido y sustancia serían las consecuencias de un mínimo criterio ético en sus realizadores sin los cuales no se entendería una función social 
ni comercial. Es muy posible que la televisión digital de la convergencia esté camino a lograr una función social rica en contenidos: culturales, informativos e irrevocablemente entretenidos, y con todo ello, sumamente educativos.

Gutiérrez Gea (2000: 2) analiza las condiciones para que la televisión sea de calidad, propuestas por un debate internacional sobre la calidad de la televisión en los países desarrollados; las seis perspectivas serían: a. Si su propósito es servir las demandas básicas del público de información, entretenimiento y ocio; b. Si respeta la pluralidad de las creencias, opiniones, tradiciones étnicas, etcétera; c. Si estimula positivamente la imaginación de los espectadores; d. Si respeta la legalidad de la cultura nacional; e. Si fomenta el conocimiento e intercambio de las diferentes tradiciones culturales; f. Si presenta trabajos de arte (novelas, dramas, operas, etcétera) de reconocida calidad.

En el caso peruano, es en la Ley 28278 de Radio y Televisión (CONCORTV, 2016), aprobada por el Congreso en junio de 2004 y promulgada por el gobierno de turno en julio de 2005, donde se estipulan los principios que garantizarían la calidad de la televisión y la radio en el país, así es como en el artículo II de la ley se estipula: a) la defensa de la persona humana y el respeto a su dignidad; b) la libertad de expresión, de pensamiento y de opinión; c) el respeto al pluralismo informativo, político, religioso, social y cultural; d) la defensa del orden jurídico democrático, de los derechos humanos fundamentales y de las libertades consagradas en los tratados internacionales y en la Constitución Política; e) la libertad de información veraz e imparcial; f) el fomento de la educación, cultura y moral de la Nación; g) la protección y formación integral de los niños y adolescentes, así como el respeto de la institución familiar; h) la promoción de los valores y la identidad nacional; i) la responsabilidad social de los medios de comunicación; j) el respeto al Código de Normas Éticas; k) el respeto al honor, la buena reputación y la intimidad personal y familiar; I) el respeto al derecho de rectificación.

Así también, en el artículo 4 de la misma ley se señala el fin de los servicios de radiodifusión, que es el de satisfacer las necesidades que las personas tienen de información, conocimiento, cultura, educación y entretenimiento "en un marco de respeto de los deberes y derechos fundamentales, así como de promoción de los valores humanos y de la identidad nacional". Mientras que en el artículo 9 se intenta profundizar en dicha finalidad con una descripción diferencial entre los servicios de radiodifusión comercial, educativa y comunitaria. En el primer caso, los servicios comerciales consistirían en la difusión de entretenimiento y recreación de los públicos además de su debida información y orientación; los servicios educativos supondrían el incentivo de la educación, la cultura y el deporte; y los servicios comunitarios en dar impulso a la identidad, costumbres e integración nacional. No obstante, se evidencia una mirada claramente excluyente entre los propósitos de entretener, educar o impulsar la identidad 
nacional y este es el punto problemático en el que se estacionan todas las buenas intenciones de una utilización óptima de los medios de comunicación y particularmente, de la televisión.

De ahí que, al cabo de trece años de emitida la ley, los públicos y expertos, cuestionen los criterios éticos y estéticos de los realizadores de contenidos televisivos de entretenimiento. Se apunta a dos razones que permiten ese tipo de programas, primero, por el bajo nivel educativo del público; y segundo, por la necesidad que tiene la televisión de sostenerse en los beneficios que le brinda la publicidad. Si el programa es de calidad pero no tiene audiencia la empresa televisiva optará por uno de menor calidad pero que le garantice altos niveles de rating; mientras que el público, lamentablemente, se inclinará con facilidad por lo que se le ofrece, que suele ser siempre aquello de menor valía; y esto porque el nivel educativo del pueblo es pobre y porque, como bien se sabe, las masas como un todo heterogéneo y desbordante, nunca tendrán el criterio suficiente para exigir mejores contenidos a los medios de comunicación.

Así también, Perla Anaya (2015: 55) observa que la propuesta legal de autorregulación ética ha sido contenida más en forma implícita que explícita en la Ley Nro. 28278 (CONCORTV, 2016). Será por ello que la misma carece de rigor exhortativo aún en lo que supone solamente una libre autorregulación pues, como se ve, la libertad empresarial y mediática se encuentra condicionada y en mucho seducida por los beneficios publicitarios.

La periodista Rosa María Palacios (comunicación personal, 17 de octubre de 2016) evidencia que a lo largo de todos estos años ninguna empresa televisiva ha respetado los estándares de calidad de la Ley 28278 (CONCORTV, 2016). Sostiene que la televisión es un negocio en el cual los contenidos tienen que ser financiados por anunciantes; y estos buscan públicos y si el público no ve programas de calidad, entonces los programas de baja calidad tendrán auspicio; un problema que la televisión siempre ha planteado. Observa que, si entre los estándares mínimos estaba la propuesta de una televisión sin violencia de 6 am a 10 am, no se ha cumplido, así como tampoco un mínimo de contenidos educativos ni respeto a la libertad de expresión. "Lo único que se ha logrado con la ley es respetar el tema de concentración, que nadie tenga más del $30 \%$ del mercado nacional, que nadie tenga en radio más del $20 \%$ del mercado local, pero después no se ha logrado nada más". Así también, considera que si bien se han abierto camino señales abiertas regionales al interior del país, no tienen posibilidades de crear contenidos de entretenimiento de calidad, por lo que optan por piratear series, novelas, ganándose serios problemas de derecho de autor.

Por otro lado, para la comunicadora, entre las fortalezas televisivas poco aprovechadas en la actualidad pese a la era digital, es su propia condición audiovisual, lo que hace que este medio tradicional, todavía sea de gran impacto y por ello, un medio potente. No obstante, se le utiliza solo para llamar la atención sobre hechos que luego serán rápidamente dejados de lado,

Question, Vol. 1, N.0 61, enero-marzo 2019. ISSN 1669-6581

Instituto de Investigaciones en Comunicación | Facultad de Periodismo y Comunicación Social | Universidad Nacional de La Plata La Plata | Buenos Aires | Argentina 
se está convirtiendo en un medio muy efímero, lo que es denuncia hoy ya no es denuncia mañana, no tiene ninguna consistencia en perseverar, y al no perseverar es irrelevante, si todos los días me pasan un asesinato, el asesinato me es irrelevante; la noticia ha perdido relevancia porque se ha banalizado (Rosa María Palacios, comunicación personal, 17 de octubre de 2016).

En esa misma dirección la directora de televisión Carla Rengifo (comunicación personal, 9 de octubre de 2016) observa que en los informativos de televisión actuales se dedican muchos más minutos a las noticias de farándula que en otros tiempos; con lo que se confirmaría una tendencia en los contenidos informativos al entretenimiento más que al propio fin de dar conocimiento de una realidad concreta para su posterior análisis.

Por todo ello, es necesaria una diferenciación entre los propósitos y funciones de la televisión, como la hay entre una misión y una visión. La misión apuntaría al aspecto funcional que corresponde a un individuo o a una entidad dentro de una sociedad; en el caso de los medios de comunicación, su función corresponde al de brindar información y entretenimiento; y su visión sería más bien compatible con el propósito de educar, pero en el sentido amplio de contribuir a la edificación y formación integral de la persona; porque en todo caso cabe la cuestión ¿para qué informar? pues si el fin es solo para satisfacer algún tipo de curiosidad resultaría este insuficiente.

\section{Viabilidad de los fines educativos de la televisión}

El ser humano es lúdico por naturaleza y, posiblemente, su mejor forma de aprendizaje siempre se ha dado a través del juego. Se podría decir que la televisión por su condición audiovisual contó desde siempre con las herramientas suficientes para hacer mensajes creativos, lúdicos e impactantes, no obstante, la conocida "caja boba" no hizo más que entorpecer el proceso de aprendizaje con el adormecimiento y la pasividad en los públicos, porque la televisión anula aquello que hace único al homo sapiens, su capacidad simbólica, la misma que se manifiesta por antonomasia con el lenguaje, la palabra y como afirma Satori (1998: 26) "en la televisión el hecho de ver prevalece sobre el hecho de hablar (...) y como consecuencia el telespectador es más un animal vidente que un animal simbólico".

De ahí que sea mucho más fácil entender por qué las funciones y propósitos de la televisión en la mayoría de los casos se han visto siempre frustrados, pues la televisión ha sido criticada 
desde sus inicios. No obstante, por su capacidad de impacto y pese a sus resultados nocivos, la televisión era conminada a educar, a ser luz en el caminar de las masas, mas con pobres resultados. Pues si bien la televisión educaba en el sentido amplio del término, lo hacía mal. Educar viene del latín educere que significa guiar, conducir; y se define como perfeccionar las facultades intelectuales y morales del niño o del joven mediante preceptos o ejemplos; así como afinar los sentidos (www.rae.es). Si se piensa en la televisión a partir de la definición de educar, se podría concluir en que resulta una de las herramientas más eficaces para dicho propósito; ya que desde sus inicios se erigió como referente conductor y guía de grandes audiencias, y con enorme facilidad para perfeccionar (o no) las facultades intelectuales y morales de los públicos.

Asimismo, otra de las acepciones de la palabra educar es doctrinar; y una muestra de que los medios de comunicación en general y la televisión en particular serían los grandes aliados de la educación en la sociedad, es que la propaganda, poderoso mensaje de adoctrinamiento, haya sido la primera estrategia utilizada a través de los medios para impactar en las masas. Haroll Laswell, estudió los efectos de la propaganda considerándola como el único medio de suscitar la adhesión de las masas (Mattelart, 2005: 32); y Carl Hovland demostró que el cambio de actitud era posible a través de los medios de comunicación si se cuidaban las condiciones necesarias y como la más indispensable, la credibilidad de la fuente (Schramm, 1982: 7), y ciertamente esta es una de las cualidades que debe cuidar todo agente educativo.

Por su parte McBride (1987: 36) considera que educar es papel importante de la comunicación, cuando afirma que dicho término vendría a ser "transmitir conocimientos a fin de promover el desarrollo intelectual, la formación del carácter y la adquisición de habilidades durante toda la vida", que a su vez coincide con la definición dada por la RAE (www.rae.es) cuando afirma que educar es perfeccionar las facultades intelectuales y morales del niño o joven (...), educar la inteligencia y la voluntad".

Así pues, desde la amplia acepción del verbo educar todos los estudios y reflexiones concluyen en que los medios de comunicación en general y la televisión en particular tienen una misión educadora transversal, que incluso, debería ser considerada como una visión, como un propósito último. Sin embargo, si se parte de una definición más reduccionista que apunta solo a establecer una analogía entre la didáctica impartida en el colegio o en la universidad, la televisión como herramienta educativa quedaría descartada, porque la didáctica precisa de la comunicación interpersonal directa o indirecta (ahora con la posibilidad que brindan las nuevas tecnologías de la comunicación) mientras que la televisión es un medio masivo.

Orozco sostiene que "encontrar educativamente provechoso un tipo de programación que no ha sido producido con una intención educativa rebasa las telenovelas y se expande hacia otros 
géneros programáticos como los talk shows, los informativos y aún la publicidad" (2001: 167), ciertamente, nadie enciende el televisor con el propósito de educarse, sino con el fin de informarse y entretenerse, y estas, desde luego, son las primeras funciones de la televisión pero que conllevan, aunque involuntariamente, un afán educativo que algunos sectores de las audiencias menos favorecidos reconocen en ella, al punto de ver a la televisión como el único medio accesible que les facilita un tipo de aprendizaje.

Los llamados programas educativos o culturales son y han sido desde siempre catalogados como aburridos y de baja sintonía, y posiblemente sea así no tanto por los formatos rígidos en que se los presentan, como por catalogarlos como educativos o culturales; pues muchos programas exitosos de entretenimiento han destacado igualmente y pese a ello, por su calidad cultural y educativa.

Si bien la sociedad es producto de la facultad y necesidad humana de comunicarse a partir de un plan trazado entre unos y otros para la consecución de objetivos de supervivencia y realización personal, la interacción comunicativa, a su vez, es solo posible dentro de un contexto socio cultural concreto que suponen unas reglas de convivencia, un lenguaje y significados que se hilvanan en una vida cotidiana constituida por espacio y tiempo. Es allí donde tiene lugar el aprendizaje que resulta intersubjetivo, como señala Schultz (citado por Ahumada, 2005) porque es en la relación con los otros que se aprende y reconoce el mundo, pues la mayoría de lo aprendido es transmitido por los padres, maestros, amigos, etcétera y también por los medios de comunicación y es aquí donde se sitúa la televisión; y más aún en un contexto social como el peruano en el que la influencia de lo audiovisual resulta determinante frente a una debilitada función orientadora de padres y maestros.

Aun cuando para algunos es previsible la desaparición de la televisión a mediano o corto plazo como consecuencia de la televisión digital, que se define como un sistema avanzado "con capacidad de recepción de sonido, texto e imágenes a gran velocidad, con la ventaja de compresión de datos, lo que permite el intercambio de estos, de forma más ágil, sin ocupar gran espacio en espectro radioléctrico" (Said, 2009: 45), su pervivencia está cada vez más supeditada a la convergencia mediática lograda en Internet. La televisión analógica está en crisis, pero inicia su renacimiento en internet, y aun cuando todavía se la pueda ver directamente a través del electrodoméstico televisor las nuevas generaciones ya acceden a todos los contenidos mediáticos únicamente a través del móvil o la computadora.

Con ello, se inaugura una nueva relación entre el espectador y la televisión, mucho más interactiva y personalizada. La televisión está ya no enfrente sino en las manos de los usuarios, quienes pasan más tiempo con ella que con los maestros y los padres. La televisión e Internet 
pasan a ser vistas como la misma cosa y su influencia resulta mucho más compleja y determinante.

En cuanto al entretenimiento como la función más reconocida de la televisión, y que suele ser contrapuesta y diferenciada del propósito educativo, se puede decir que, por el contrario, no difiere de ella en su esencia, pues el entretenimiento no es otra cosa que una forma de continuo aprendizaje por su condición recurrente, lúdica y creativa. El lenguaje audiovisual desde sus inicios, reconocido por su naturaleza entretenida y de impacto, fue aprovechado y explotado por los rusos en su exploración del montaje cinematográfico con un fin concreto. Sergei Eisenstein proponía un proceso en el que el espectador pase de la imagen al sentimiento y del sentimiento a la idea; es así que fundamenta cómo el espectador "debe ser sometido a estímulos de acción psicológica y sensorial, a través de 'mecanismo de montaje', con el fin de producirle un choque emotivo" (Morales Morante, 2009: 2), por lo que la capacidad expresiva del espectáculo no está tanto en el hilo argumental de la obra sino en la construcción del montaje, en la manera en cómo se planifica la puesta en escena y se cuenta la historia. Por tanto, la captura de la atención a partir de la atracción dominante que supone una puesta en escena que enseguida despierta admiración, sorpresa o conmoción en el espectador, impacta en este de tal forma que activa sus emociones y lo predispone al pensamiento y a la reflexión, con lo que se inicia el proceso de aprendizaje. Así es como se puede entender que un informativo o una telenovela, ya por el tratamiento de la información propuesto, ya por las actitudes y comportamientos de los actores y conductores, deslizan una alternativa de aprendizaje que llega al espectador no siempre de modo consciente.

Joan Ferrés (1996: 2) se sorprende de que mientras los padres, educadores y espectadores consideran que la influencia está en el discurso (vía racional, verbal); los grandes especialistas de la persuasión, es decir, los asesores de imagen, publicistas y políticos, saben que más bien la influencia está en el relato (vía emocional, imagen), ya que en ellos el discurso ideológico está enmascarado mediante la fascinación de la acción y de la emoción. Es esa concepción ingenua del entretenimiento, señala el autor, lo que coloca en situación vulnerable a los espectadores y lo que convierte al entretenimiento en el sistema de socialización, intencional o no, más eficaz. Ferrés recuerda las palabras de Herbert Schiller cuando afirmaba tajantemente que "el aserto de que el entretenimiento no es instructivo debe catalogarse como una de las supercherías más grandes de la Historia" (Ferrés, 1996: 3).

Se puede concluir que en general los contenidos televisivos tienen una consecuencia educativa, ya si se tratare de una teleducación o de un "eduentretenimiento". La teleducación es una propuesta que de manera explícita ve en la televisión una herramienta aliada al sistema educativo, tal como fue la concepción originaria en los inicios de la televisión peruana, cuando 
se veía en dicho medio una herramienta educativa eficaz que complementaría la instrucción escolar y que se reflejó en la pronta realización de programas tales como TV en el aula o La telescuela del 7. No obstante, en la actualidad, esa orientación solo se espera de la televisión pública ya que la televisión comercial se siente exenta de dicho propósito.

Por otro lado, el "eduentretenimiento" podría entenderse más bien como un necesario tomar conciencia de las consecuencias educativas de los contenidos televisivos, y proponerse su aprovechamiento, ya que todos ellos, de manera inexorable, pueden ser percibidos por las audiencias como fuentes de formación como es el caso de aquellas madres latinoamericanas de clase baja que "encuentran educativas las telenovelas comerciales y recomiendan a sus hijos e hijas verlas para que 'aprendan de la vida', lo que no es el resultado de una perversión materna de las audiencias femeninas, señala Orozco (2001: 167), sino la constatación de sus posibles percepciones de la televisión".

El "eduentretenimiento" por ser un estilo de hacer televisión comprende todos los formatos y géneros televisivos. No solo una telenovela sino un programa informativo, una serie o incluso la publicidad televisiva tendrían como resultado un efecto positivo en las audiencias, con la contribución a su culturización, al refuerzo de valores y costumbres y con la adquisición de conocimientos útiles para resolver problemas cotidianos o para tomar decisiones de vida. Desde esta óptica se podría afirmar que el "eduentretenimiento" sería la opción más eficaz para hacer televisión en tanto que no se pierde de vista el fin primordial que es entretener sin descuidar el aspecto formativo que imparten sus contenidos.

\section{Contenidos que entretienen y educan}

Si los productores, comunicadores y audiencias lo decidieran el "eduentretenimiento" sería totalmente viable en la televisión de señal abierta, pues es evidente que la articulación de estos tres involucrados en la realización televisiva resulta crucial, no obstante, no han sido suficientes las propuestas de diálogo y estudio de las audiencias por parte de los canales con el fin de conocer sus usos y expectativas de programación ni las audiencias están lo suficientemente organizadas y comprometidas con el tema para arreglar la televisión. No obstante, el panorama cambia con la televisión digital que resultaría ser "uno de los mayores catalizadores y agentes de la Sociedad de la Información y el Conocimiento" (Said, 2009: 48), en tanto que, como parte de Internet, la televisión apuesta por contenidos más amplios y uniformemente entretenidos e informacionales. 
Con todo ello, la programación televisiva peruana orientada al "eduentretenimiento" ha sido posible en el canal del Estado, TV Perú, televisora que evidentemente ha pasado de contenidos educativos intencionales a programas mucho más dinámicos y flexibles que sin perder naturalidad resultan más eficaces si acaso hubiera una intención educativa. La telenovela Nuestra Historia podría ser un ejemplo de ello, acogida por la audiencia por su carácter histórico al contextualizar la trama en tres décadas decisivas en la historia del país; así también el programa Sucedió en el Perú, que tiene dieciséis años al aire con un formato dinámico flexible y profundamente ilustrativo. El éxito de estos programas, aun cuando se podría afirmar que son educativos por el canal en el que se emiten, sería el resultado de sus buenos contenidos y del empeño puesto en que sean verdaderamente entretenidos.

Por lo demás, son blanco de crítica constante los programas de entretenimiento de los canales comerciales de señal abierta por el morbo, el sensacionalismo, la erotización, la violencia física y verbal presentes en casi todos sus contenidos (Montalván, 2016). La Asociación sin fines de lucro Valores Humanos, una de las pocas entidades constituidas por personas civiles con el fin de monitorear los contenidos de la televisión peruana, sostiene que la televisión nacional cambiará con la especial colaboración de los empresarios mediáticos, ya que solo así se podrá desacostumbrar al espectador peruano de contenidos nocivos con la propuesta de programas de calidad.

Los jóvenes de ahora ven mucha televisión y el medio televisivo, según Salomón Lerner Febres, tiene el poder de formar los gustos del público e incluso incidir en su forma de pensar. Los chicos toman como referente a los protagonistas de los realities y quieren vivir su mundo de fatuidad y promiscuidad. Son muy pocos los que ven la televisión con sentido crítico (Ibídem).

Un ejemplo peruano de programa de entrenamiento que hasta bien podría haberse delineado como "eduentretenimiento" es Esto es Guerra, un programa juvenil que si no fuera por el comportamiento y polémicas implicaciones entre los protagonistas participantes podría haber sido un programa promotor de sanas competencias; no obstante, la propuesta implícita era la del reality con el desarrollo de conflictos y rivalidades entre los participantes que trascendían la pantalla hasta convertirse en polémicas noticias de los diarios populares.

Este tipo de distorsiones son frecuentes en los contenidos de señal abierta cuyo propósito es la obtención inmediata de audiencia. De esa parte, la televisión de señal cerrada, en cambio, por su tematización ha devenido en "eduentretenimiento" aun cuando no en todos los casos; no 
obstante, estos contenidos resultan mucho más ilustrativos e informativos que los transmitidos por la señal abierta y sin dejar de ser sumamente entretenidos.

La implicación, característica de los realities, no debería pasar por complicidades y conflictos propiciados adrede entre los protagonistas y participantes de un programa de entretenimiento, sino por otro tipo de vinculaciones reales y positivas, tal como la puesta en evidencia de la vivencia de un auténtico de espíritu de grupo, entre el equipo de realizadores y participantes. Mateus Borea (2008) sostiene que emocionar e implicar deberían ser las nuevas metodologías pedagógicas; desde luego, el factor emotivo de un programa de entretenimiento puede ser eficazmente explotado si se descartan los usos más recurrentes como son los eventos sentimentales como excusa para incentivar el morbo.

En una encuesta realizada por el diario El Comercio (Meza, 2010) sobre cuáles serían los diez programas más exitosos en la historia de la televisión peruana, las audiencias determinaron que aquellos serían los siguientes: el programa concurso conducido por Augusto Ferrando Trampolín a la fama, que salió al aire por Panamericana Televisión en los años setenta hasta inicios de los noventa; el programa humorístico Risas y Salsa, emitido también por Panamericana Televisión de 1980 a 1999 con la sucesiva presentación de sketches protagonizados por vedettes y personajes de la farándula peruana hoy muy bien conocidos como Adolfo Chuiman, Gisela Valcárcel, Analí Cabrera, Carlos Álvarez, etcétera. El programa infantil Nubeluz conducido por las Ilamadas dalinas Mónica Santamaría y Almendra Gomelsky, que salió al aire por Panamericana Televisión en 1990 y que con el tiempo también despertó el interés de televisoras de otros países latinoamericanos y europeos.

Así también, Magaly TeV", el polémico programa de espectáculos, emitido por ATV, que cosechó muchas críticas por el tratamiento informativo que hacía de los destapes relacionados con la vida privada de personajes públicos. Qué hay de nuevo con Jaime Bayly, programa de entrevistas que salió al aire en 1991 por Panamericana Televisión, conducido por el famoso periodista que entrevistaba a personajes nacionales e internacionales. Disco Club, programa musical que pasaba videos de estreno de los mejores artistas de rock del momento, conducido por Gerardo Manuel y que se mantuvo 25 años al aire por TVPerú; Triki Trak conducido por Luís Ángel Pinasco y Sonia Oquendo, programa concurso de corte familiar que salió al aire por América Televisión de 1986 hasta 1992; El show de los sueños programa de espectáculos conducido por Gisela Valcárcel, emitido por América Televisión; la serie Al fondo hay sitio emitido por América Televisión de 2009 a 2016; y finalmente el programa deportivo Goles en acción emitido en los años noventa por Global TV.

Desde luego que esta lista de programas exitosos fue determinada por la audiencia, por lo que no precisamente figuran en ella programas de probada calidad ética y creatividad. 
Frecuentemente el rating siempre resulta el criterio más importante para determinar el éxito de un programa de televisión. En la lista citada, por ejemplo, fueron muy criticados programas como Trampolín a la fama, Risas y Salsa, Magaly TeVe, entre otros que figuran en la lista y que desplazan a programas tan reconocidos como Los niños y su mundo o El mundo de los niños, programas infantiles conducidos por Yolanda Polastri que permanecieron en el aire durante muchos años y gozan ahora de la aceptación y aprecio de críticos y espectadores.

Luego de la realización de sucesivas entrevistas a personas vinculadas a la televisión, Perla Anaya (2015: 207) subraya tres aspectos en los que todos ellos coinciden; los conductores, productores, periodistas o animadores de televisión coinciden en primer lugar en una preocupación por la ética en la televisión, ya que reconocen que existe una crisis sin precedentes en la actualidad; en segundo lugar, insisten en una "dictadura" del rating, "identificado como el verdadero mandamás de la televisión nacional, el que en última instancia impone la programación, incluso antes que los anunciantes y el público" (Ibídem: 208); y finalmente, coinciden en la complicidad que tiene el público con el decaimiento ético de la televisión. Enfatizan en que si no mejora el nivel educativo del público no mejorarán sus niveles de exigencia, pues el público finalmente consume lo que reprocha.

No obstante, si estos son los desafíos y desaciertos de la televisión analógica, la televisión digital se presenta como parte de la enciclopedia interactiva que supone Internet y por ello con posibilidades de que la televisión no vuelva a ser la misma, pues la naturaleza de la red implica de todas formas el uso del lenguaje escrito, por tanto, los nuevos consumidores de televisión digital han de leer y escribir para aprovechar la interacción que propone el medio de la convergencia.

Así, también lo digital ha favorecido la existencia de una televisión local que ha dado relieve a la proximidad y con ello, al aumento de canales temáticos, consolidándose la desmasificación de la televisión (Fuente-Alba, 2013), no obstante la fuerza que adquiere la televisión a través de Internet hace que cada vez se integre más y la televisión analógica vaya en declive.

\section{Bibliografía}

Ahumada, R. (2005). La TV y la educación ¿una red interconectada? Barcelona: Plaza y Valdés.

Cabrera, J. (2006). Como dioses en el ciberespacio: Hacer televisión en la era de la Internet. Razón y Palabra, 11(54). 
Consejo Consultivo de Radio y Televisión (CONCORTV) (2016). Ley de Radio y Televisión No 28278. Recuperado de http://www.concortv.gob.pe/wp-content/uploads/2016/07/Leyde-radio-y-television.pdf

Ferrés, J. (1996). Televisión subliminal, socialización mediante comunicaciones inadvertidas. Barcelona: Paidós.

Fuente-Alba, F. (2013). La televisión local ante el abismo de la Televisión Digital Terrestre. Santiago de Chile: RIL editores-Editorial UCSC.

Gomá, J. (26 de octubre de 2015). Conferencia. Parte 1 [archivo de video]. Recuperado de https://www.youtube.com/watch?v=D7Xgw2QkrdQ

Gutiérrez Gea, C. (2000). Televisión y calidad: Perspectivas de investigación y criterios de evaluación. Zer, 9.

Mattelart, A. (2005). Historia de las teorías de la comunicación. Madrid: Paidós.

Mateus Borea, J. (2008). El mito de la pantalla que educa. Televisión y educación en el Perú: tensiones y posibilidades. La mirada de Telemo, 1. Recuperado de https://bit.ly/2RblahY

McBride, S. (1987). Un solo mundo, voces múltiples. México DF: Fondo de Cultura Económica.

Meza, D. (14 de noviembre de 2010). Los 10 programas más exitosos de la televisión peruana. Recuperado de http://elcomercio.pe/tvmas/television/10-programas-mas-exitosostelevision-peruana-noticia-668832

Morales Morante, L. (2009). Serguei Eisenstein: montaje de atracciones o atracciones para el montaje. Recuperado de https://bit.ly/2LSpUDr

Orozco Gómez, G. (2001). Audiencias, televisión y educación: una deconstrucción pedagógica de la 'televidencia' y sus mediaciones. Revista Iberoamericana de Educación, 027. Recuperado de http://www.redalyc.org/pdf/800/80002708.pdf

Perla Anaya, J. (2015). Ética de la comunicación televisiva. Lima: Fondo Editorial de la Universidad de Lima.

Said, E. (2009). Transformaciones comunicativas en la Era Digital. Hacia el apagón analógico de la televisión. Barranquilla: Ediciones Uninorte.

Sartori, G. (1998). Homo Videns. La sociedad teledirigida. Buenos Aires: Taurus.

Schramm, W. (1982). La ciencia de la comunicación humana. México DF: Editorial Grijalbo.

Yazigi, C. (2011). Reseña de El espectador emancipado de Jacques Ranciére. Aisthesis, 50. Recuperado de http://www.redalyc.org/articulo.oa?id=163221476015 